\title{
Luxación rotatoria atlantoaxoidea en adulto
}

\author{
Adult atlantoaxial rotational dislocation
}

\author{
Luis Gerardo Domínguez Gasca, ${ }^{*}$ Arturo Reyes Mares, ${ }^{*}$ Luis Gerardo Domínguez Carrillo ${ }^{\ddagger}$
}

Mujer de 24 años, profesionista, sin antecedentes de importancia, quien inició su padecimiento tres meses atrás al efectuar una rutina de defensa personal (judo). Al contactar con el piso, su cuello sufrió una rotación, quedando el mentón en contacto con el hombro izquierdo. Inicialmente no presentó dolor, pero 24 horas después notó que su cabeza giraba hacia la izquierda de manera automática, logrando voluntariamente llevarla a posición neutra, sin poder efectuar rotación a la derecha más allá de la línea media.

Recibió tratamientos no especificados y utilizó diferentes collarines sin obtener mejoría, por lo que acudió a medicina general, en donde se le diagnosticó tortícolis espasmódica,
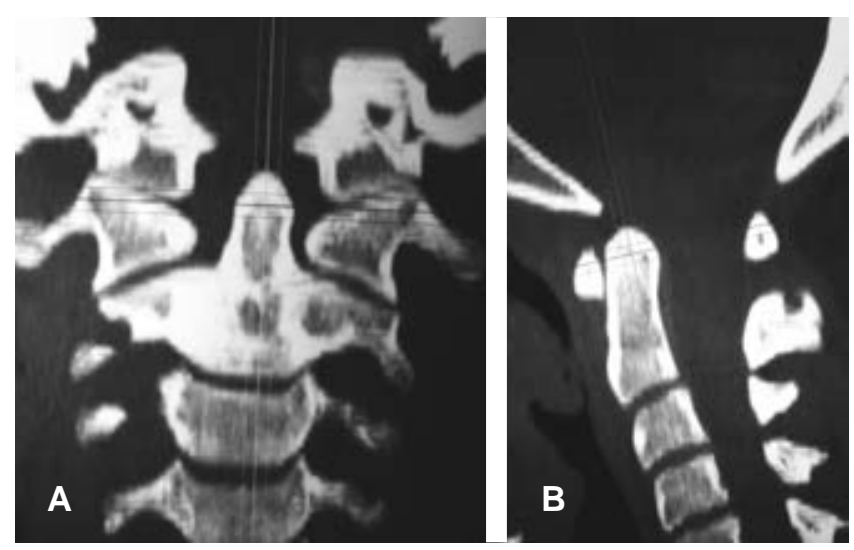

Figura 1: Tomografía computarizada de la columna cervical que muestra: (A) Plano coronal. Asimetría de las distancias de la apófisis odontoides a las masas laterales del atlas; (B) Plano sagital. Distancia normal entre la odontoides y el arco anterior del atlas, que corresponden a la integridad del ligamento transverso. prescribiendo relajantes musculares. Sin embargo, al no obtener modificación se le derivó a Rehabilitación.

A la exploración en rehabilitación la paciente se encontró asintomática, con rotación de cabeza hacia la izquierda a $80^{\circ}$, posición de Cock-Robin, que se restituye voluntariamente a posición neutra, pero, al relajarse, regresa a la posición original de manera involuntaria; flexión y extensión de la columna cervical moderadamente disminuidas e imposibilidad para la rotación a la derecha. Se observó prominencia del músculo esternocleidomastoideo derecho, sin incremento en el tono muscular de las paravertebrales cervicales; el resto de la exploración fue normal. Por las características clínicas se llegó al diagnóstico de luxación

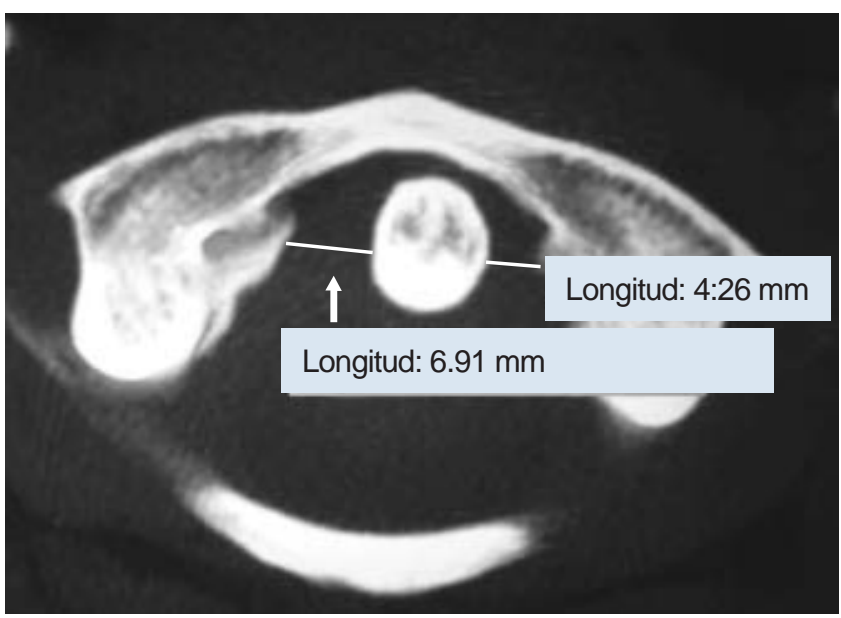

Figura 2: Imagen tomográfica en corte axial, que evidencia una asimetría de las distancias del odontoides a las masas laterales del atlas y que corresponde a luxación rotatoria atlantoaxoidea.

Correspondencia:

Dr. Luis Gerardo Domínguez Gasca

Correo electrónico: luisdom88@hotmail.com

Aceptado: 06-06-2019.
* Especialista en Traumatología y Ortopedia. Cirugía Articular, División de Cirugía del Hospital Ángeles León. León, Guanajuato, México.

* Especialista en Medicina de Rehabilitación. Profesor de la Facultad de Medicina de León, Universidad de Guanajuato. México. 

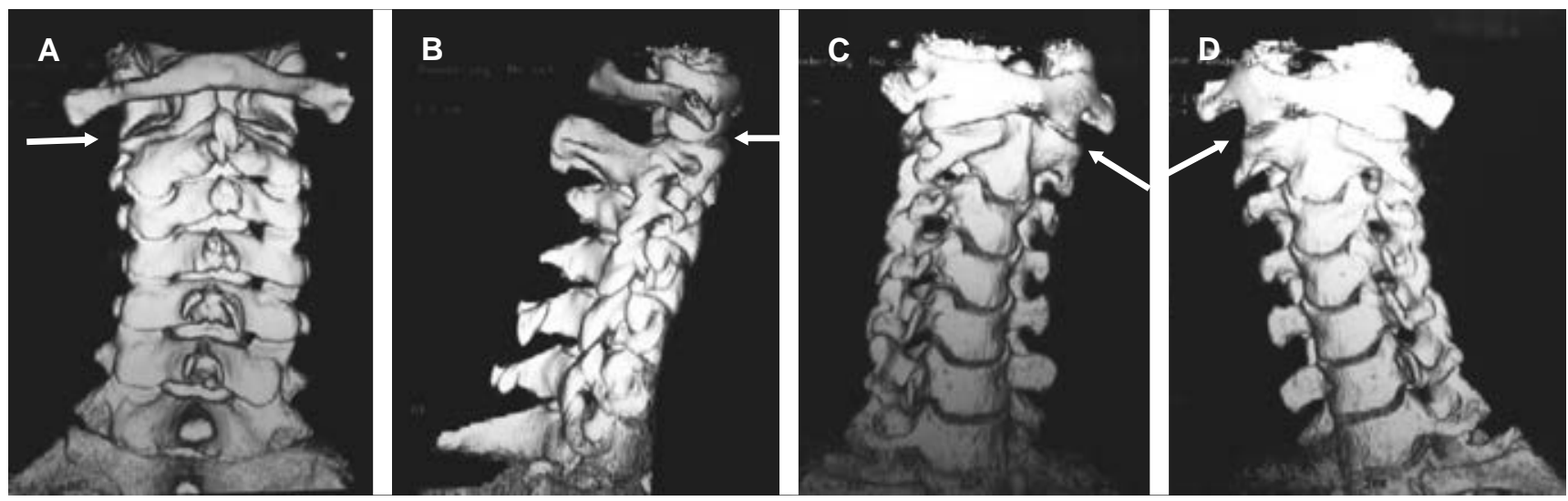

Figura 3: Imágenes tomográficas de la columna cervical en reconstrucción 3D, que corresponde a la vista posterior en plano frontal (A), plano sagital (B), vista oblicua derecha (C) y oblicua izquierda (D), y que además muestran un desplazamiento de las masas laterales del atlas (flechas) que corresponden a una luxación rotatoria atlantoaxoidea.

atlantoaxoidea rotatoria, por lo que se solicitó tomografía computarizada, la cual corroboró el diagnóstico, siendo de tipo I en la clasificación de Fielding, ${ }^{1}$ permaneciendo el ligamento transverso intacto (Figuras 1 a 3). Por el tiempo de evolución (tres meses) se derivó a neurocirugía para valoración de reducción.

La luxación atlantoaxoidea rotatoria en adultos es poco frecuente; ${ }^{2}$ habitualmente no se asocia con síntomas neurológicos. El mecanismo de lesión es la flexoextensión brusca con un componente rotatorio de columna cervical. ${ }^{3}$ En niños se ha descrito como síndrome de Grisel, ${ }^{4}$ sin existir antecedente de traumatismo. Las radiografías de odontoides pueden mostrar asimetría en relación con las masas laterales del atlas, con estrechamiento o superposición unilateral de las articulaciones apofisiarias. El estudio de elección es la tomografía, ${ }^{5}$ el tratamiento durante las primeras 24 a 48 horas es la tracción cervical en decúbito supino y los ejercicios activos son de amplitud de movimiento. Al lograse la reducción se utiliza inmovilización con collarín rígido ambulatorio y ejercicios activos para recuperar la movilidad; ${ }^{3}$ la artrodesis posterior $\mathrm{C} 1-\mathrm{C} 2$ rara vez es requerida. ${ }^{5}$

\section{REFERENCIAS}

1. Fielding JW, Hawkins RJ, Ratzan SA. Spine fusion for atlanto-axial instability. J Bone Joint Surg Am. 1976; 58 (3): 400-407.

2. Yang SY, Boniello AJ, Poorman CE, Chang AL, Wang S, Passias PG. $A$ review of the diagnosis and treatment of atlantoaxial dislocations. Global Spine J. 2014; 4 (3): 197-210.

3. Martín-Ferrer S. Traumatismos de la columna cervical alta: clasificación tipológica, indicaciones terapéuticas y abordajes quirúrgicos (a propósito de 286 casos). Neurocirugía. 2006; 17: 391-419.

4. Domínguez CL, Trujillo SM, Segovia A. Síndrome de Grisel, luxación rotatoria atlanto-axoidea. Acta Med. 2005; 3: 103-107.

5. Mönckeberg JE, Tomé CV, Matías A, Alonso A, Vásquez J, Zubieta JL. CT Scan study of atlantoaxial rotatory mobility in asymptomatic adult subjects: a basis for Better Understanding C1-C2 rotatory fixation and subluxation. Spine (Phila Pa 1976). 2009; 34 (12): 1292-1295. 